\title{
SEM Analysis on Electron Arc Furnace Dust (EAFD) and EAFD-Asphalt Mixture
}

\author{
Mohammad A. T. Alsheyab ${ }^{1}$ \\ ${ }^{1}$ Qatar National Research Fund, Department of Civil and Environmental Engineering, Qatar \\ Correspondence: Mohammad A. T. Alsheyab, Qatar National Research Fund, Department of Civil and \\ Environmental Engineering, Qatar. E-mail: malsheyyab@gmail.com
}

Received: October 20, 2013 Accepted: November 18, 2013 Online Published: November 27, 2013

doi:10.5539/enrr.v3n4p147 URL: http://dx.doi.org/10.5539/enrr.v3n4p147

\begin{abstract}
Electric Arc Furnace Dust (EAFD) is a by-product of steelmaking industry which has been classified as hazardous. The considerable amounts produced per ton of steel, estimated by $15-20 \mathrm{~kg} / \mathrm{ton}$, make it a serious environmental problem that should be addressed. One of the solution scenarios is the use of Solidification/stabilization technology and one of potential candidates is the asphalt as a widely used material in road construction. This paper had an insight view on the microstructure of EAFD and its mixture with asphalt using the scanning electron microscopy (SEM). The scanning results showed that the EAFD small particles fill the air voids in asphalt and those of bigger size get attached to the surface. This was confirmed by the specific gravity and penetration tests.
\end{abstract}

Keywords: Electric Arc Furnace Dust (EAFD), Scanning Electron Microscopy (SEM), asphalt cement, asphalt mixture

\section{Introduction}

Currently there are four methods used worldwide for the production of steel: (1) the elastic blast furnace/basic oxygen furnace, (2) Direct melting of scrap by electric arc furnace, (3) smelting reduction and (4) direct reduction. The process of steelmaking industry using the direct melting by electric arc furnace consists in furnace charging; melting; refining; slag foaming and casting. During the process the fumes are formed and extracted through an aperture, post-combusted, cooled and cleaned in from of dust, known as electric arc furnace dust (EAFD) (Hille et al., 1997; European commission, 2001).

Apart from the wastes and by-products caused by the process, substantial emissions to air are causes as well; these include wide range of inorganic compounds such as iron oxide dust and heavy metals and refractory organic o pollutants (Remus, Aguado-Monsonet, Roudier, \& Sanch, 2013).

The EAFD has been classified as a hazardous waste attributed to containing hazardous and leachable elements such as zinc, lead or cadmium (Alsheyab \& Khedaywi, 2013; Guézennec, Huber, Patisson, Sessiecq, Birat, \& Ablitzer, 2005; Cubukcuoglu \& Ouki, 2009; Pavao, De Vargas , Masuero, Dal Molin, \& Vilela , 2009). Therefore the management and treatment of this by-product has been gaining

higher and higher attention to protect the environment of its possible risk, especially when highlighting the fact that per each ton of produced steel, there are about $15-20 \mathrm{~kg}$ of generated dust. Although this was estimated to be around 3.7 million tons worldwide, it gets increasing each year (Néstor \& Borja , 2003).

Many methods of treatment were reported including recovery of valuable metals (iron, zinc and lead), using in cement/concrete industry as raw material, use in glass-ceramic industry and use as additive to asphalt cement (AK, 2013).

Alsheyab and Khedaywi reported that the addition of EAFD to asphalt cement produced appropriate mixture with asphalt properties suitable for road construction. This was proved by the values of Penetration Index for all studied samples, which was between -2 and +2 for all of them, according to ASTM D946/D946M - 09a (AK, 2013).

A continuation to that result, this paper will investigate the mixture structure of EAFD and asphalt on a micro level by scanning electron microscopy (SEM) to gain further knowledge of the EAFD particles structure, 
morphology and their chemical Composition as well as the EAFD particles structure and distribution when it is mixed with asphalt with different percentages. This will explain the change of asphalt properties and the impact of mixing the EAFD with asphalt.

There are about 13 steel factories in Jordan and the case study factory produces 25-30 EAFD/ton steel and according to the factory the produced dust is stored underground without any treatment. Knowing that this dust is hazardous and could harm the environment, especially the underground water, this drove the authors of this paper to find an environmentally sound solution.

\section{Material Used and Laboratory Work}

\subsection{Electric Arc Furnace Dust (EAFD)}

EAFD was provided by United Iron and Steel Manufacturing Company in Jordan and it was characterized at the laboratories of the Natural Resources Authority in Jordan. The results of analysis are summarized in Table 1, where it shows that the major components are ferric oxide $\left(\mathrm{Fe}_{2} \mathrm{O}_{3}=39.2 \%\right)$ and zinc oxide $(\mathrm{ZnO}=18.7 \%)$.

Table 1. Electric arc furnace dust composition

\begin{tabular}{cc}
\hline Compound & $\mathrm{Wt} \%$ \\
\hline $\mathrm{Fe}_{2} \mathrm{O}_{3}$ & 39.3 \\
$\mathrm{MnO}$ & 2 \\
$\mathrm{TiO}_{2}$ & 0.34 \\
$\mathrm{CaO}$ & 8.96 \\
$\mathrm{~K}_{2} \mathrm{O}$ & 0.25 \\
$\mathrm{P}_{2} \mathrm{O}_{5}$ & 0.35 \\
$\mathrm{SiO}_{2}$ & 6.2 \\
$\mathrm{Al}_{2} \mathrm{O}_{3}$ & 1.52 \\
$\mathrm{MgO}$ & 3.22 \\
$\mathrm{Na}_{2} \mathrm{O}$ & 3.87 \\
$\mathrm{SO}_{3}$ & 2.5 \\
$\mathrm{Cl}$ & 5.27 \\
$\mathrm{ZnO}$ & 18.7 \\
L.O.I & 7 \\
Others & 0.52 \\
\hline
\end{tabular}

\subsection{Asphalt}

One penetration grade of asphalt cement (60-70) was used in this study. Asphalt was obtained from the Jordan Petroleum Refinery Company in Zerqa/Jordan, and it is widely used in flexible pavement construction. Table 2 presents the physical properties of this asphalt.

Table 2. Physical properties of asphalt used in this study

\begin{tabular}{lll}
\hline Properties & Methods & Test Result \\
\hline Penetration $(0.1 \mathrm{~mm}), 25^{\circ} \mathrm{C}, 100 \mathrm{~g}, 5 \mathrm{sec}$ & ASTM D 5 & 65 \\
Ductility $(\mathrm{cm})$ at $25^{\circ} \mathrm{C}$ & ASTM D 113 & 108 \\
Specific gravity at $25^{\circ} \mathrm{C}$ & ASTM D 70 & 1.010 \\
Softening point $\left({ }^{\circ} \mathrm{C}\right)$ & ASTM D 36 & 50.3 \\
Flash Point $\left({ }^{\circ} \mathrm{C}\right)$ & ASTM D 92 & 312.5 \\
Fire Point $\left({ }^{\circ} \mathrm{C}\right)$ & ASTM D 92 & 318 \\
\hline
\end{tabular}




\subsection{Laboratory Work and Scanning Electron Microscopy Analysis}

\subsubsection{Preparation of Mixture and Characterization}

It has been decided to study different volume percentages of EAFD - asphalt binder. The studied percentages are: $5,10,15$ and $20 \%$ of EAFD by volume of binder. For each experiment, the corresponding weight to each volume percentage for both the asphalt and EAFD was prepared. The asphalt was heated while adding the corresponding volume of EAFD with mixing to guarantee a homogeneous mixture for each experiment. Mixtures were left to cool down to ambient temperature.

\subsubsection{SEM Analysis}

Samples of EAFD, asphalt and their mixture were sent to the laboratories of Al-Albait University in the north of Jordan for SEM analysis. Two magnitudes of 4000 and 10000 were chosen.

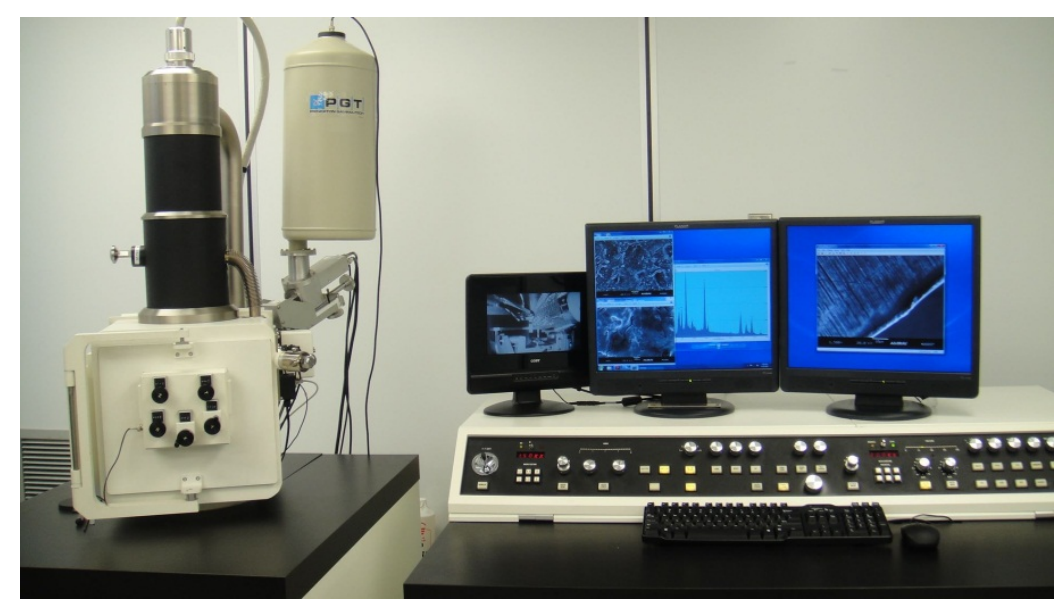

Figure 1. Microscopy Laboratory- Scanning Electron Microscopy equipment

SEM is a microscope that uses electrons instead of light to form an image of a sample in a raster scan pattern by utilizing a beam of electrons which documents a samples morphology and structure. The scanning electron microscope has advantages over traditional microscopes by producing detailed magnified pictures of incoming samples.

These Electrons from the SEM Analysis interact with the atoms from within the sample to produce an output that shows the samples composition, surface topography, electrical conductivity, as well as a variety of other properties. Some samples have to be kept in specific states to be tested properly or coated and prepared to produce a higher quality image.

\subsubsection{Specific Gravity (ASTM D 70)}

It is the ratio of the weight of a sample to the weight of an equal volume of water. It is needed to determine weight-volume relationships and to calculate various volume related quantities such as air voids and voids in mineral aggregate (VMA).

\subsubsection{Penetration Test (ASTM D 5)}

The penetration test is an empirical measure of asphalt consistency. The test consists of allowing a prescribed needle, weighted to $100 \mathrm{~g}$ to bear on the surface of the asphalt cement, at $25^{\circ} \mathrm{C}$, for $5 \mathrm{~s}$. The distance, in units of $0.1 \mathrm{~mm}$, penetrated by the needle into the EAFD-asphalt mixture is taken as the measurement.

\section{Results and Discussion}

The SEM analysis was performed for EAFD at two particle sizes of $\mathrm{x} 4000$ and $\mathrm{x} 10000$ before mixing. 


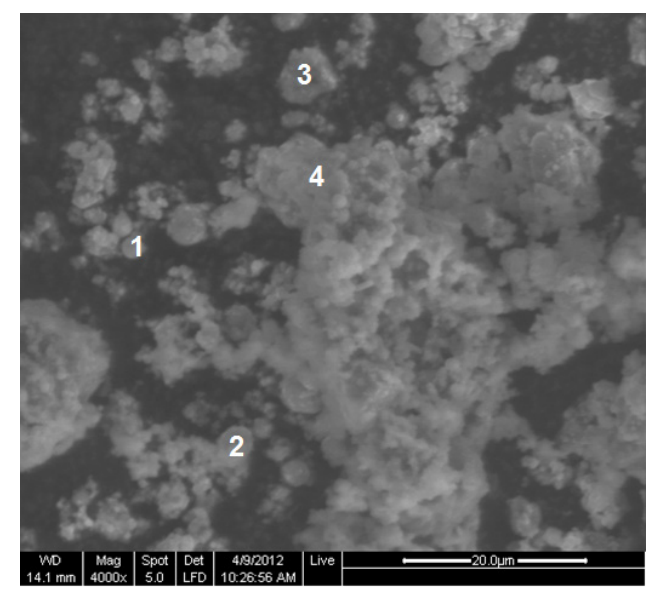

Figure 2. Metallographic structure of the EAFD particles, (x4000)

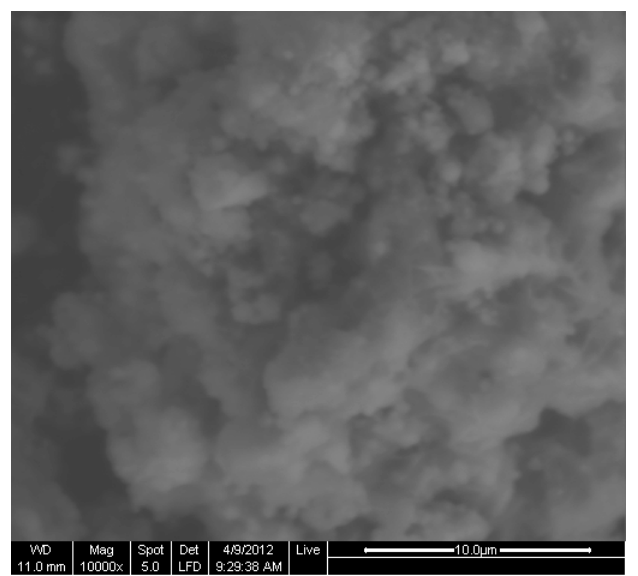

Figure 3. Metallographic structure of the EAFD particles, (x10000)

Figure 2 shows that the EAFD is found in clots, points 3 and 4, and separated particles, points 1 and 2, and seems that the particles are spherical. The picture also shows irregular voids represented by the black areas around the particles. When the magnitude of scanning was increased from $\times 4000$ to $\times 10000$, the picture obtained is shown in figure 3 . This picture would be a result of scanning points like 3 and 4 in Figure 1 where the particles seem to be very attached to each other with almost no voids. These pictures could explain the nature of the mixture of EAFD and how its components are reflected in producing a non-homogeneous structure. This should be affected by the size of different elements of the components such as Fe, $\mathrm{Zn}, \mathrm{Al}, \mathrm{Mn}$ etc. and the adhesion forces between these components.

Also a SEM was performed for asphalt at $\mathrm{x} 4000$ as shown in Figure 4. 


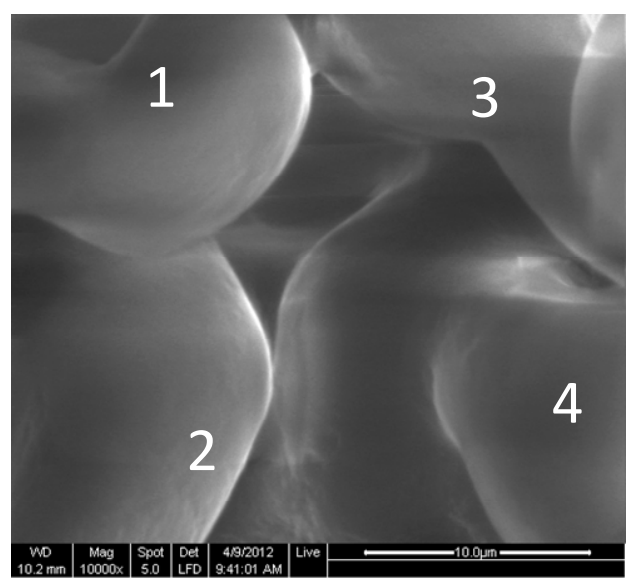

Figure 4. SEM of asphalt material at (x4000)

The SEM of asphalt shows clearly the voids and the structure of asphalt. It shows that the surface areas of molecules as well. The picture shows that the structure is almost homogeneous because of the similar adhesion forces between the particles of asphalt. Points 1,2,3 and 4 look very similar.

After mixing the studies mixtures with volumes of 5, 10, 15 and 20\% of EAFD, SEM analysis was performed for each sample at both magnitudes of x4000 and x10000. The results are shown below in Figures 5 and 6.

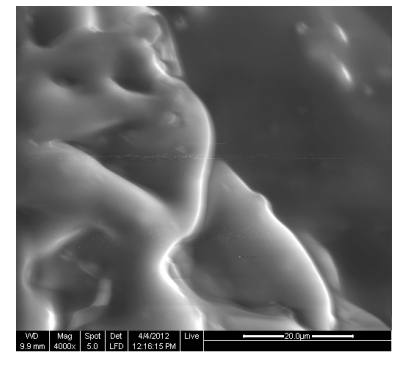

$5 \%$ EAFD

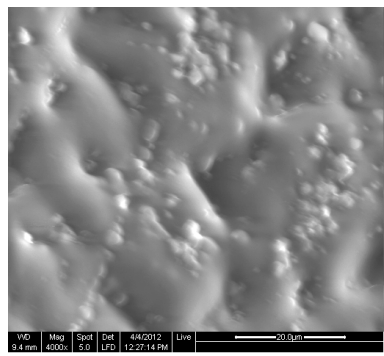

$10 \%$ EAFD

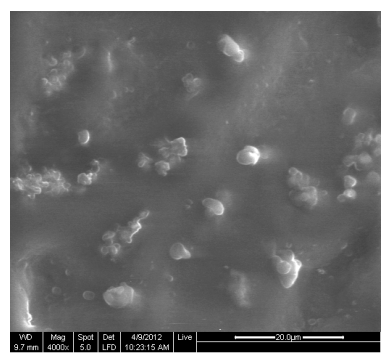

$15 \%$ EAFD

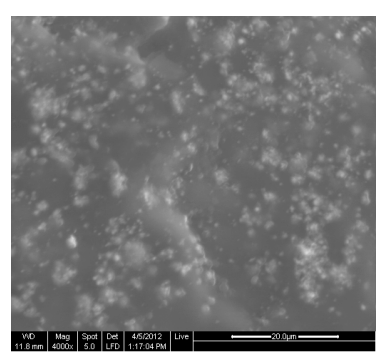

$20 \%$ EAFD

Figure 5. SEM analysis for asphalt-EAFD mixtures of volumes 5,10,15 and 20\% volume of EAFD performed at $\mathrm{x} 4000$

Figure 5 shows that with the increase of EAFD volume added to asphalt, there are fewer voids and the surface becomes more homogeneous. This could be explained by that the particles of dust will be covered with asphalt layers and this will reduce the voids in asphalt and as we add more particles the voids will be fewer and fewer. In $20 \%$ EAFD, the voids seem to be completely filled. This would increase the adhesion between the asphalt particles.

The above explanation was confirmed when we increased the scanning magnitude from $\mathrm{x} 4000$ to $\mathrm{x} 10000$ seen in Figure 6, where we can see how the EAFD particles are embedded in the asphalt and how the voids are being filled as a result of the addition of EAFD. The picture of $15 \%$ EAFD shows that the voids are filled with the particles and they start to appear on the surface and the picture of 20\% EAFD shows more particles on the surface. This may produce irregular structure of the mixture and therefore lower cohesion forces. 


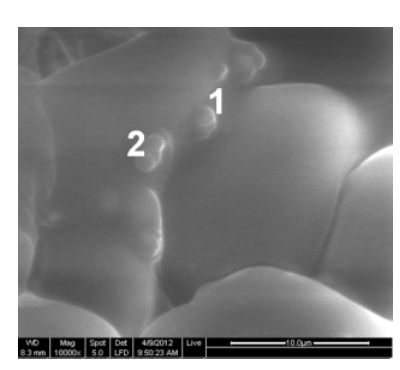

$5 \%$ EAFD

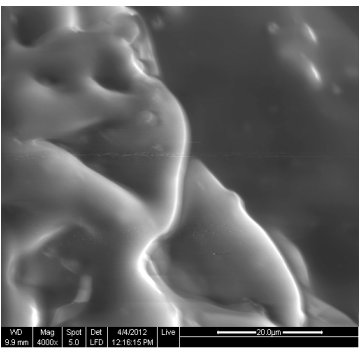

$10 \%$ EAFD

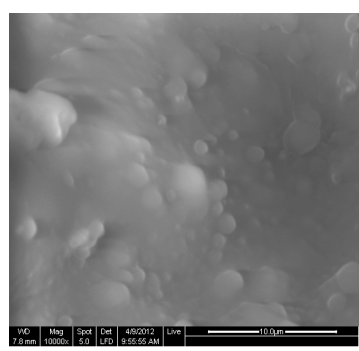

$15 \%$ EAFD

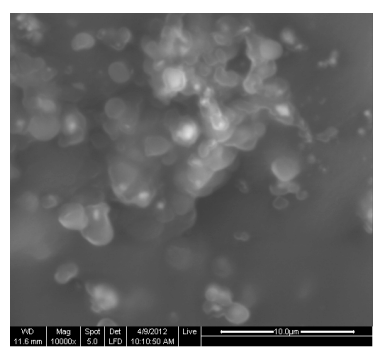

$20 \%$ EAFD

Figure 6. SEM analysis for asphalt-EAFD mixtures of volumes 5,10,15 and 20\% volume of EAFD performed at $\mathrm{x} 10000$

To validate the scanning of the mixtures of asphalt with EAFD, the penetration values for each percentage of EAFD added to asphalt was measured and the results are shown in Figures 7 and 8.

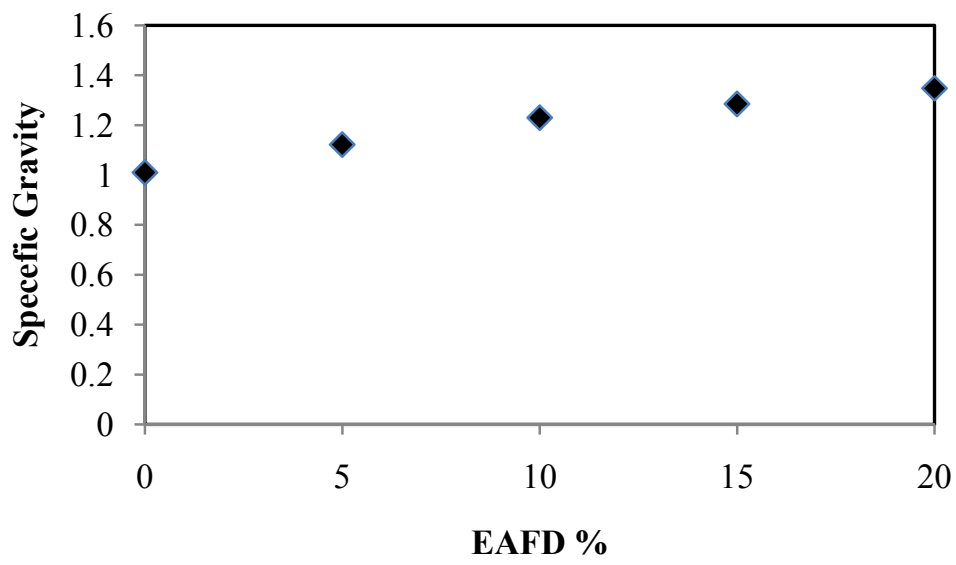

Figure 7. Effect of EAFD on specific gravity (AK, 2013)

The results shows that the specific gravity was increasing with the increase of EAFD percentage which means that the air voids became less and less with the increase of EAFD. This goes in line with the scanning pictures of the mixture samples as explained above. 


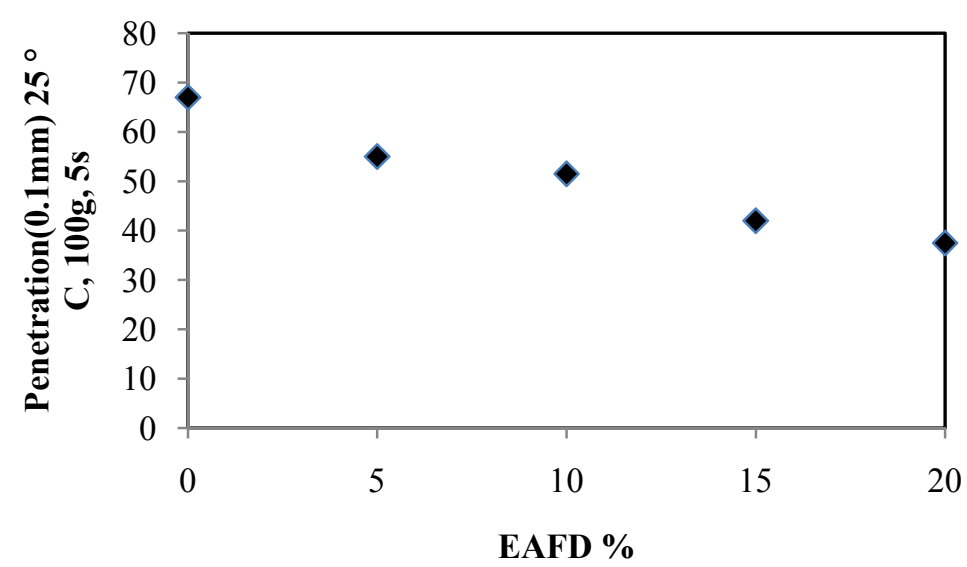

Figure 8. Effect of EAFD on penetration (AK, 2013)

The results of penetration test showed that it was decreasing with the increase of EAFD \% added to asphalt which is another confirmation of the scanned pictures of the samples. This means that the voids are being filled with the EAFD particles and therefore it makes more resistant to penetration and therefore more consistency of the mixture.

\section{Conclusions}

Scanning electron microscopy was performed for EAFD and the prepared mixtures, to gain further knowledge of the EAFD particles structure, morphology and their chemical Composition as well as the EAFD particles structure and distribution when it is mixed with asphalt with different percentages. The following was observed in SEM:

1) The scanning of EAFD showed that most particles of EAFD are spherical, some are separated and the majority is gathered in clots. It shows also that the spherical particles are heterogeneous and have different diameters.

2) The scanning of asphalt showed a homogeneous structure with voids in between.

3) The scanning of the mixture showed that the EAFD were being covered with layers of asphalt and the voids were less as it is expected that the smaller particles of EAFD filled the voids and those of bigger diameter were attached to the surface.

4) The tests of specific gravity and penetration confirmed the scanning pictures and both support the belief that the small particles of EAFD fill the air voids in asphalt and the bigger size gets attached to the surface of asphalt particles.

\section{Acknowledgments}

Authors are grateful to Abdulhameed Shoman Fund for Supporting Scientific Research for funding this project and United Iron and Steel Manufacturing Company in Jordan, in particular to Eng. Mohammad Shawabkeh for their cooperation and providing the research project with the necessary samples of EAFD.

\section{References}

European Commission. (2001). BREF on the Production of Iron and Steel. European Commission, Sevilla.

Cubukcuoglu, B., \& Ouki, S. K. (2009). The use of alternative constituents in cement-based solid-ification/stabilization of electric arc furnace dust. Proceedings of the 7th international conference on sustainable management of waste and recycled materials in construction. WASCON.

Guézennec, A. G., Huber, J. C., Patisson, F., Sessiecq, P., Birat, J. P., \& Ablitzer, D. (2005). Dust formation in electric arc furnace: birth of the particles. Powder Technology, 157(1-3), 2-11.

Hille. (1997). Wirtschaftliche Betrachtungen zur Entwicklung der Hochofenkapazitaeten in der Welt. Economical Considerations of the Development of Blast Furnace Production Capacities in the World (pp. 93-101).

Mohammad, A. T. A., \& Taisir, S. K. (2013). Effect of electric arc furnace dust (EAFD) on properties of asphalt 
cement mixture. Resources, Conservation and Recycling, 70, 38-43.

Néstor, G. G., \& Borja, G. E. V. (2003). The situation of EAF dust in Europe and the upgrading of the Waelz process. Waste Treatment and Clean Technology, 99(2), 1511-1520.

Pavao, B., De Vargas, A. S., Masuero, A. B., Dal Molin, D. C., \& Vilela, A. C. (2009). Influence of electric arc furnace dust (EAFD) in alkali-activated fly ash binder. Proceedings of the 11th international conference on non-conventional materials and technologies (NOCMAT'09).

Rainer, R., Miguel, A., Aguado, M., Serge, R., \& Luis, D. S. (2013). Best Available Techniques (BAT) Reference Document for Iron and Steel Production. Industrial Emissions Directive 2010/75/EU (Integrated Pollution Prevention and Control).

\section{Copyrights}

Copyright for this article is retained by the author(s), with first publication rights granted to the journal.

This is an open-access article distributed under the terms and conditions of the Creative Commons Attribution license (http://creativecommons.org/licenses/by/3.0/). 